\title{
BMJ Open Uppsala Longitudinal Adolescent Depression Study (ULADS)
}

\begin{abstract}
Iman Alaie, ${ }^{1}$ Anna Philipson, ${ }^{2}$ Richard Ssegonja, ${ }^{3}$ Lars Hagberg, ${ }^{2}$ Inna Feldman, ${ }^{3}$ Filipa Sampaio, ${ }^{3}$ Margareta Möller, ${ }^{2}$ Hans Arinell, ${ }^{1,4}$ Mia Ramklint, ${ }^{1,4}$ Aivar Päären, ${ }^{1}$ Lars von Knorring, ${ }^{4}$ Gunilla Olsson, ${ }^{1}$ Anne-Liis von Knorring, ${ }^{1}$ Hannes Bohman, ${ }^{1}$ Ulf Jonsson ${ }^{1,5,6}$
\end{abstract}

\begin{abstract}
To cite: Alaie I, Philipson A, Ssegonja R, et al. Uppsala Longitudinal Adolescent Depression Study (ULADS). BMJ Open 2018;9:e024939. doi:10.1136/ bmjopen-2018-024939

- Prepublication history and additional material for this paper are available online. To view these files, please visit the journal online (http://dx.doi. org/10.1136/bmjopen-2018024939).
\end{abstract}

Received 21 June 2018 Revised 31 October 2018 Accepted 19 December 2018

Check for updates

(c) Author(s) (or their employer(s)) 2018. Re-use permitted under CC BY-NC. No commercial re-use. See rights and permissions. Published by BMJ.

For numbered affiliations see end of article.

Correspondence to

Dr Ulf Jonsson;

ulf.jonsson@neuro.uu.se

\section{ABSTRACT}

Purpose To present the Uppsala Longitudinal Adolescent Depression Study, initiated in Uppsala, Sweden, in the early 1990s. The initial aim of this epidemiological investigation was to study the prevalence, characteristics and correlates of adolescent depression, and has subsequently expanded to include a broad range of social, economic and health-related long-term outcomes and cost-of-illness analyses.

Participants The source population was first-year students (aged 16-17) in upper-secondary schools in Uppsala during 1991-1992, of which 2300 (93\%) were screened for depression. Adolescents with positive screening and sex/agematched peers were invited to a comprehensive assessment. A total of 631 adolescents ( $78 \%$ females) completed this assessment, and 409 subsequently completed a 15year follow-up assessment. At both occasions, extensive information was collected on mental disorders, personality and psychosocial situation. Detailed social, economic and health-related data from 1993 onwards have recently been obtained from the Swedish national registries for 576 of the original participants and an age-matched reference population $(\mathrm{N} \geq 200000)$.

Findings to date The adolescent lifetime prevalence of a major depressive episode was estimated to be $11.4 \%$. Recurrence in young adulthood was reported by the majority, with a particularly poor prognosis for those with a persistent depressive disorder or multiple somatic symptoms. Adolescent depression was also associated with an increased risk of other adversities in adulthood, including additional mental health conditions, low educational attainment and problems related to intimate relationships. Future plans Longitudinal studies of adolescent depression are rare and must be responsibly managed and utilised. We therefore intend to follow the cohort continuously by means of registries. Currently, the participants are approaching mid-adulthood. At this stage, we are focusing on the overall long-term burden of adolescent depression. For this purpose, the research group has incorporated expertise in health economics. We would also welcome extended collaboration with researchers managing similar datasets.

\section{INTRODUCTION}

Unipolar depression is recognised as one of the leading causes of disability worldwide $^{12}$ and is associated with medical morbidity, mortality and diminished quality of life. ${ }^{3}$ Depressive disorders have also been

\section{Strengths and limitations of this study}

- Uppsala Longitudinal Adolescent Depression Study is based on a well-characterised and comparatively large community cohort assessed with structured diagnostic interviews in both adolescence and adulthood.

- The national registries available in the Nordic countries enable continuous follow-up of the cohort with limited attrition and comprehensive data.

- This cohort has been followed for up to 25 years, spanning from the formative years in childhood and adolescence--through emerging and young adulthood-to full-fledged adulthood.

- The combination of diagnostic interviews and a wide range of register-based social, economic and health-related variables offers a unique opportunity to estimate the long-term outcomes and societal costs associated with adolescent depression.

- The generalisability of the results is restricted by the demographic and historical context of the cohort.

linked to substantial impairments across several important domains, with regard to overall educational, occupational and social functioning. ${ }^{4}$ Recent research points to the high cost of illness related to depression and other mental health disorders, further underscoring the societal challenge posed by these conditions. $^{5-9}$ The 12-month prevalence of depression is estimated to be about $6 \%$ in the adult general population, ${ }^{10}$ with a strong female preponderance (about 2:1). ${ }^{11}$ Similar estimates have been reported for mid-to-late adolescence. ${ }^{12-14}$ A growing body of research from epidemiological investigations indicates that first onset of depression frequently occurs in adolescence, and evidence suggests an increasing cumulative probability rising from around 5\% in early adolescence to $20 \%$ in late adolescence. ${ }^{1516}$ In addition, a substantial proportion of adolescents present with subthreshold symptoms and go undiagnosed or untreated, ${ }^{1718}$ despite an elevated risk for future adversity. ${ }^{19}$ This emphasises the need 
for efficacious prevention and early treatment for those affected. ${ }^{20}$

To inform judicious policy-making and treatment planning, the full extent of the long-term burden following early-onset depression must be considered. This includes mental and general health, adult role functioning, and related societal costs. Further, clinical subtyping using diagnostic criteria has highlighted the relevance of distinguishing between persistent and episodic depressive disorders. ${ }^{21} 22$ For this purpose, longitudinal studies of diagnostically well-characterised samples followed prospectively from childhood or adolescence into adulthood are required, with repeated outcome assessments covering the full scope of social, economic and health-related outcomes. As clinical samples are unlikely to be fully representative of the broader group of children and adolescents with diagnosable depressive disorder, the cohorts should ideally be drawn from the general population.

Community-based longitudinal studies of adolescent depression are rare, ${ }^{23}$ presumably reflecting the considerable investment of time and effort needed to establish and maintain data collection over time. The few available cohorts must therefore be cherished and utilised responsibly. There are a few highly influential longitudinal community-based cohort studies, in which early-onset depressive disorders have been reliably assessed using established diagnostic criteria. ${ }^{24-29} \mathrm{~A}$ central feature of these epidemiological investigations is the repeated follow-up assessments from childhood or adolescence over the transition to adulthood, with particular attention to health-related and functional outcomes (table 1). ${ }^{1922 \text { 24-42 }}$ Participants in all of the available cohorts followed into adulthood were born in the 1970s or early 1980s. Each cohort has its own distinct characteristics and merits, and collectively they have contributed vastly to our current understanding of the natural course of adolescent depression. It is now well established that both major depressive disorder (MDD) and subthreshold depression, with first onset in childhood or adolescence, are linked to recurrent episodes of depression and other mental health conditions in adulthood. ${ }^{23}$ The pattern of empirical findings on adult social and economic outcomes, on the other hand, is less clear-cut. While results consistently have shown that children and adolescents suffering from depression are at risk of a range of adverse psychosocial outcomes in adulthood, ${ }^{43}$ some studies suggest that these associations are attributable to contextual factors, adolescent functioning or continued depression in adulthood. ${ }^{3744}$ However, a presumably non-trivial limitation of most available studies looking at the adult social and economic outcomes of early-onset depression is the sole reliance on self-reported information. Using self-report might be sufficient for a rough approximation, yet there is the risk of recall bias. In addition, individuals might be reluctant to report potentially sensitive information about, for instance, personal income, social welfare recipiency and number of sick-days. More detailed and objective data are therefore essential to obtain precise estimates.

This article details the design, cohort characteristics and relative strengths and weaknesses of the Uppsala Longitudinal Adolescent Depression Study (ULADS). ULADS shares several features with other available longitudinal studies of adolescent depression, but also has some unique qualities. ULADS engaged a total population of first-year students in upper-secondary schools in the town of Uppsala, Sweden, during the early 1990s, and has subsequently been followed for up to 25 years. In comparison to other longitudinal studies of earlyonset depression, this sample included a relatively large number of participants with a child or adolescent depressive disorder $(n=274)$. This presents a rare opportunity to shed new light on the long-term burden of adolescent depression. The participants have been followed up in person once, after 15 years, which is less frequent than most of the other available cohort studies. Conversely, the national registries held by government agencies in Sweden provide detailed data with limited attrition for virtually each consecutive year since the cohort was recruited. Sweden and other Nordic countries provide extensive resources for register-based epidemiological research, as the existence of personal identity numbers allows unambiguous linkage to various national registries kept by government agencies. The registries include ample data on healthcare utilisation (eg, prescription drugs, specialised healthcare), finance (eg, income, unemployment, sick leave, social welfare assistance), educations (eg, grade point average, higher education), family formation (eg, childbearing, marriage, divorce) and criminal offences. The extensive research output based on these registries has advanced scientific progress in both medicine and social sciences. ${ }^{45-47}$

Previous publications from ULADS have focused on adolescence (ages 16-17) and outcomes in young adulthood (ages 19-30). The study has now entered a new phase, as the cohort is approaching mid-life. At this stage, we will primarily focus our research efforts on three overarching objectives:

1. To estimate the long-term social, economic and health-related outcomes of specific subtypes of adolescent depression (ie, persistent depressive disorder, episodic MDD and subthreshold depression).

2. To identify moderators and mediators of these outcomes.

3. To apply health economic methods to the dataset, including cost-of-illness analyses and development of a generic probabilistic health economics model for longterm cost-effectiveness analyses of interventions targeting adolescent depression.

The available descriptions of ULADS are dispersed over a number of publications spanning over several decades. A comprehensive overview of the cohort could therefore be helpful for the research community, ahead of our forthcoming efforts. The purpose of the present cohort profile is to outline each distinct wave of data collection 


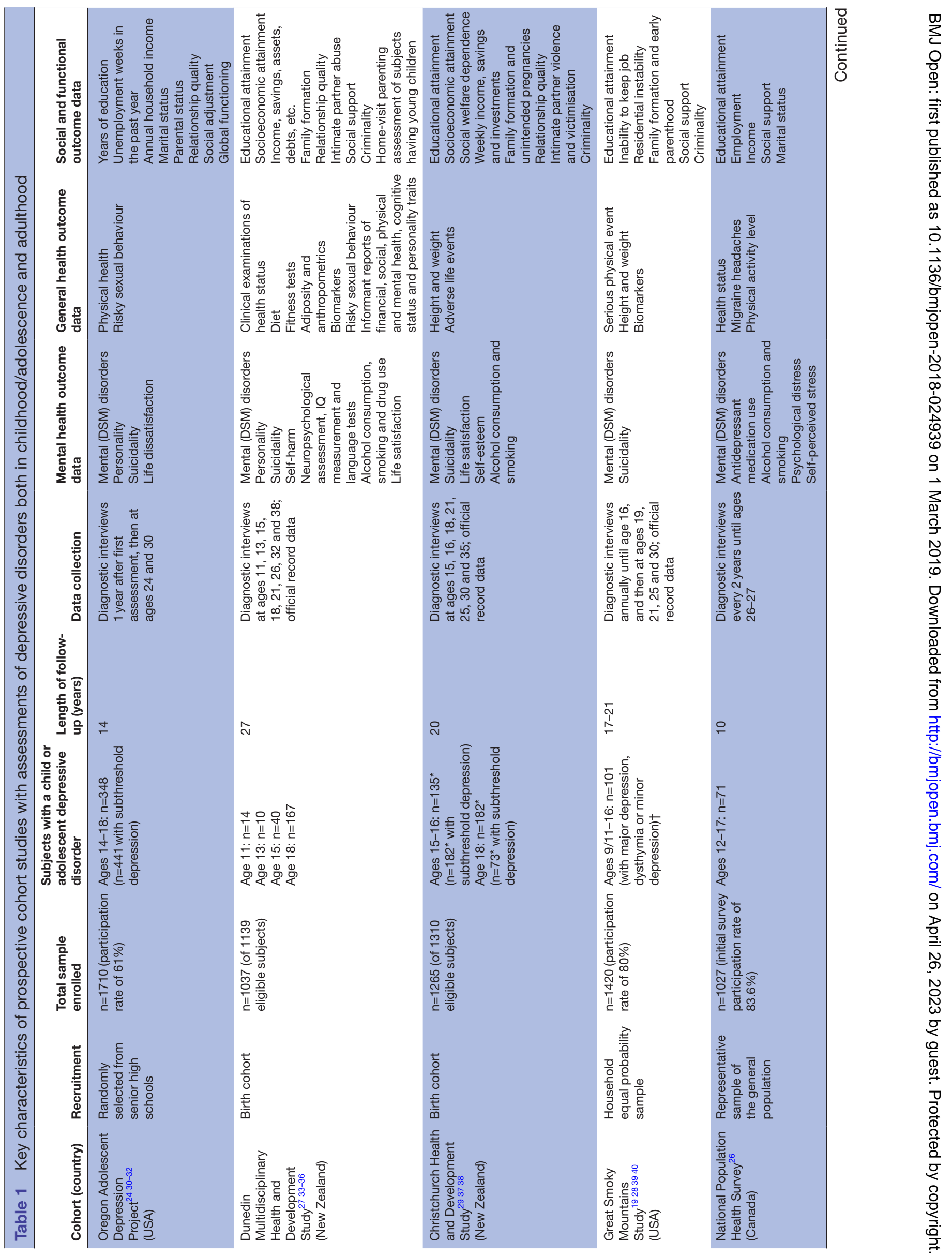




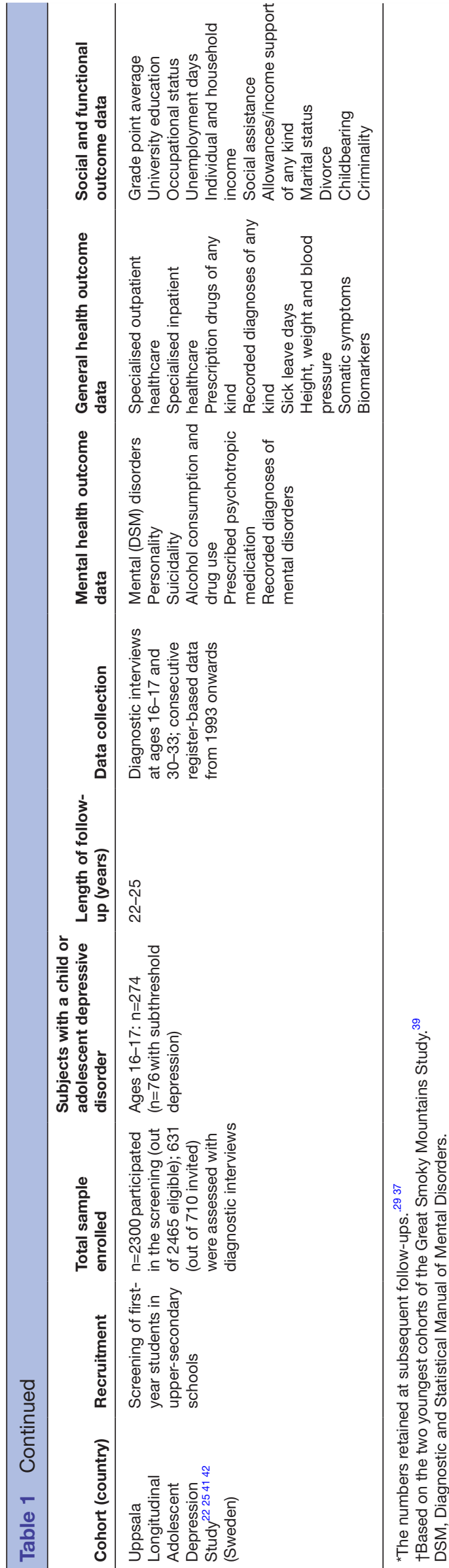

from the early 1990s onwards and provide a description of the available data. The presentation should also be viewed as an invitation to researchers managing similar datasets to contact us for collaboration or exchange of ideas.

\section{COHORT DESCRIPTION}

\section{Recruitment and study flow}

This epidemiological investigation involved a total population of first-year students aged 16-17 in upper-secondary schools in the town of Uppsala, Sweden, in 1991-1992. Due to logistic reasons, some of the nine schools were enrolled in 1991, and the others in 1992. Adolescents of the same age group who had dropped out of school were also actively invited. Uppsala is a university town, with approximately 180000 inhabitants in the early 1990s.

Out of a total of 2465 eligible adolescents, 2300 (93\%) participated in a screening for depression by means of two self-report questionnaires: the Beck Depression Inventory-Child (BDI-C) ${ }^{48}$ and the Center for Epidemiological Studies-Depression Scale for Children (CES-DC). ${ }^{49}$ Despite repeated efforts to include the 183 adolescents who had dropped out of school, only 97 (53\%) accepted. Adolescents with positive screening (BDI $\geq 16,{ }^{50}$ or CES-DC $\geq 30+\mathrm{BDI} \geq 11,{ }^{51}$ or a self-reported suicide attempt) were invited to take part in a comprehensive face-to-face assessment including a structured diagnostic interview (Diagnostic Interview for Children and Adolescents in the Revised form according to DSM-III-R for Adolescents; DICA-R-A) ${ }^{52}$ For each student with positive screening, a same-sex classmate with negative screening was invited to an identical assessment. A total of 710 adolescents were invited to this assessment, of which 631 (78\% females) participated (see table 2 for sample characteristics). Participants consented to future contact by providing their unique personal identity number, which is assigned to all Swedish citizens and all foreign residents planning to live in Sweden for at least 1 year. Figure 1 provides a flow chart of the recruitment and the baseline diagnostic assessment.

A second wave of data collection was completed about 15 years after the baseline assessment, in 2006-2008, when the participants were $30-33$ years old. The participants who had consented to be contacted $(n=609)$ were invited to a follow-up interview focusing on mental health, general health and psychosocial outcomes. Written information about the study was sent to the participants by mail, after which a member of the research group contacted the participants by phone to provide an opportunity for questions and additional information. A total of 409 participants completed this follow-up interview. In addition, register-based data, clustered into groups based on whether the participants had a depressive disorder in adolescence or not, were obtained in this phase.

Participants attending the follow-up interview were invited to a third wave of data collection in 2011-2013, when they were 33-36 years of age. A total of 188 


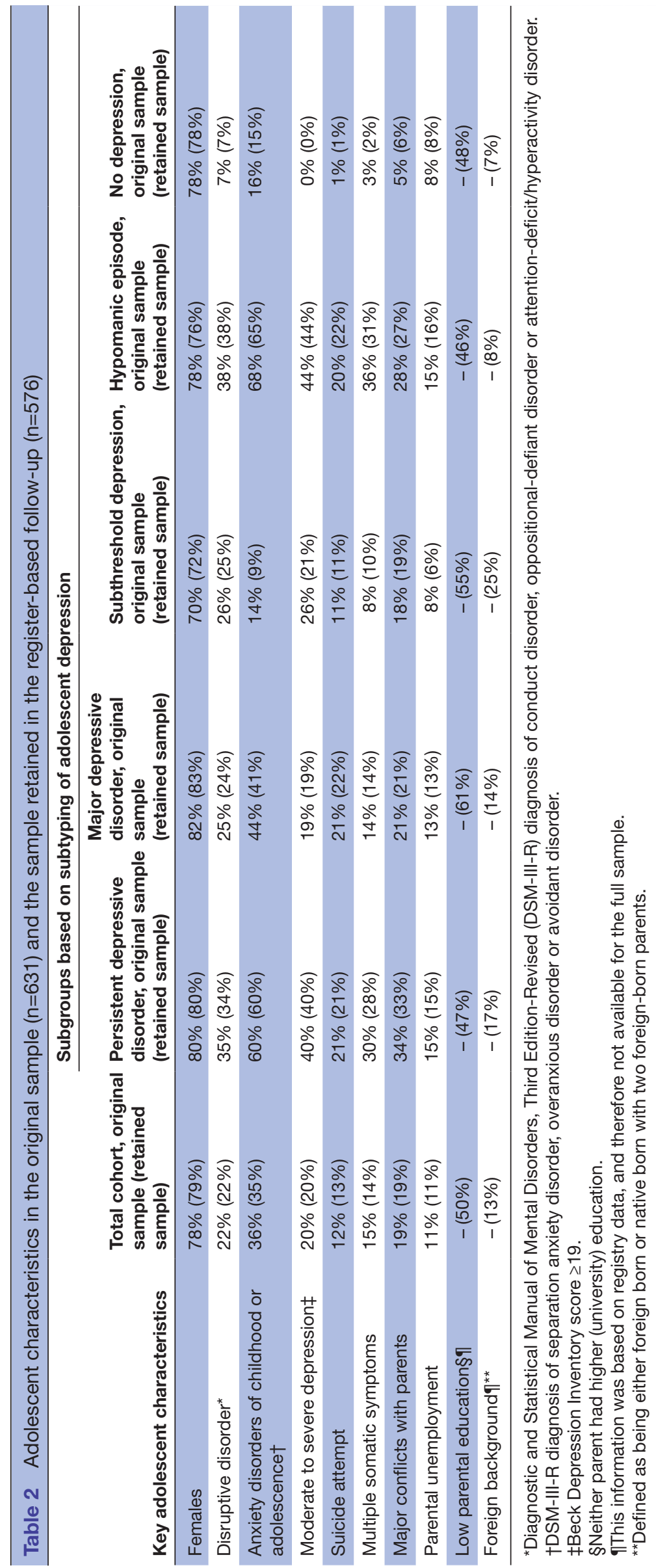

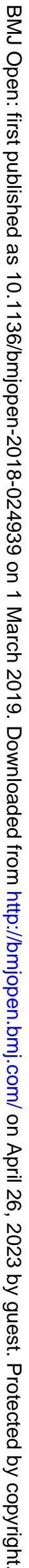


Baseline assessment (ages 16-17)

Diagnostic interview (child and adolescent mental disorders), depressive symptoms, personality, life events, social network, somatic symptoms

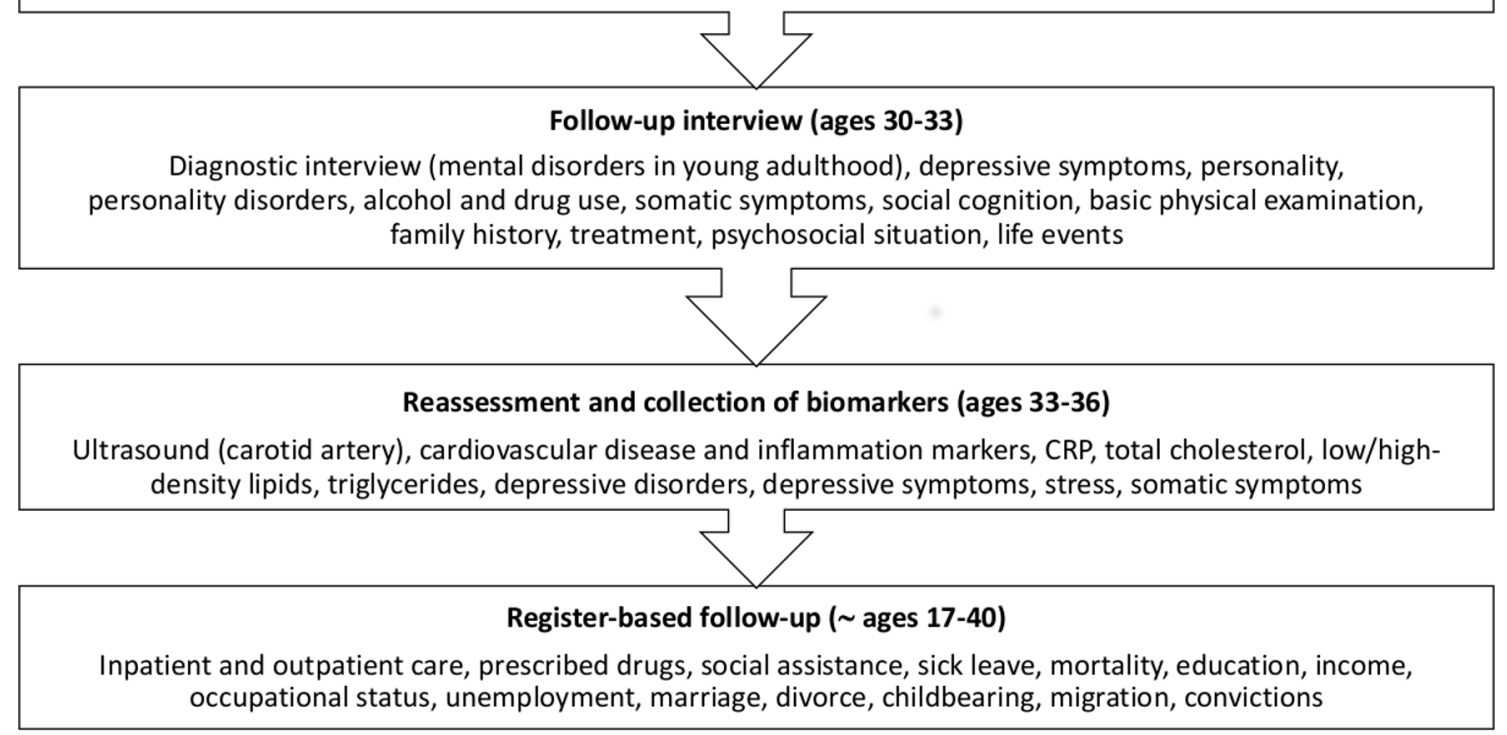

Figure 1 Phases of the study and data available from each phase. CRP, C-reactive protein.

participants took part in this assessment, which focused on early signs of atherosclerosis and other risk markers for cardiovascular disease.

Currently, when the participants approach mid-adulthood, we are consecutively extending our prospective data collection by means of extensive information from national registries. The currently available register-based data, spanning from 1993 (or the first available year for each registry) to 2014/2015/2016 (depending on data accessibility at the time when data were requested), cover detailed information on finance, occupational status, educational attainment, civil state and family formation, healthcare utilisation and criminal offences. These registry data were linked to our original dataset, including the diagnostic assessments from previous study phases, by Statistics Sweden. Data were then returned to the research group in an anonymised form. No participant was contacted directly at this stage. These anonymised data were obtained for 576 of the 631 original participants $(91 \%)$, excluding participants who at baseline did not give consent to further participation $(n=22)$, or who subsequently refused extraction of individualised registry data as a part of the follow-up assessment at ages 30-33 $(n=33)$. This procedure was approved by the Regional Ethical Review Board in Uppsala. Each of the previous waves of data collection was approved by either the same board or former local ethical vetting boards at Uppsala University.

The procedure from the baseline assessment onwards is outlined in figure 2 , while table 3 provides information about attrition at each phase of the study.

\section{Baseline assessment (ages 16-17)}

A blinded diagnostic interview (DICA-R-A) was performed by one psychiatrist, two psychologists, two psychiatry nurses and one student. All interviewers were individually trained by the same psychiatrist and any uncertainties were resolved by consensus decisions. In a subset of 27 interviews, another psychiatrist recorded scorings simultaneously as the interviewer. No kappa value is available from the baseline assessment. However, no differences in diagnostic results were found, only minor discrepancies in details. Further, all interviews were conducted during school hours, as soon as possible after screening. The participants also responded to a set of self-report questionnaires covering personality traits (Karolinska Scale of Personality), ${ }^{53}$ significant life events (Children's Life Events Inventory), ${ }^{54}$ social network (Interview Schedule for Social Interaction, self-report) ${ }^{55} 56$ and somatic symptoms (Somatic Symptom Checklist Instrument; SCI). ${ }^{57}$

\section{Follow-up interview (ages 30-33)}

Eligible participants were invited to take part in a faceto-face assessment, including a blinded diagnostic interview (Mini International Neuropsychiatric Interview 5.0.0 Plus; MINI-PLUS). ${ }^{58}$ The interview was supplemented with additional questions and a life chart spanning from late adolescence onwards to facilitate recollection of previous episodes of depression and mania/hypomania. Five interviewers trained in clinical psychology or psychiatry conducted these follow-up interviews, and any uncertainties were regularly discussed with senior psychiatrists in order to ensure clinical validity of the diagnoses and increase reliability. One randomly chosen interview for each interviewer was video recorded and co-rated by the other interviewers, which yielded an overall (for all the included diagnoses in MINI-PLUS) free-marginal kappa value of 0.93 .

In addition, the participants were interviewed about their past and present social situation, significant life 
All first-year students in upper-secondary school and adolescents of the same age-group not attending school, in Uppsala, Sweden, 1991-92

$n=2465,53 \%$ females

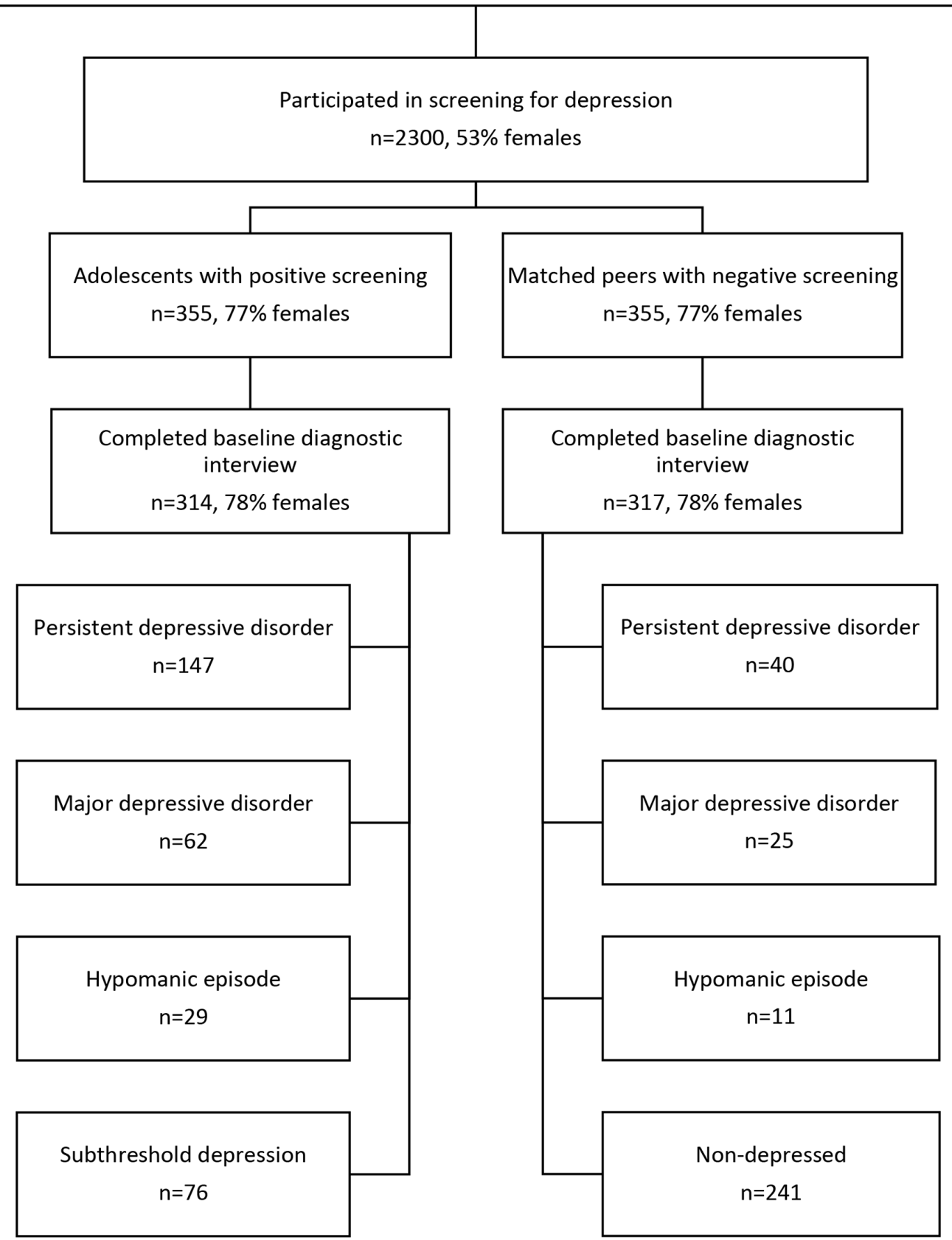

Figure 2 Flow chart of the screening procedure and baseline diagnostic assessment.

events, healthcare and family history of mental disorders based on predefined survey questions. The survey questions also covered lifetime experiences of psychiatric outpatient and inpatient treatment, psychotropic medication, psychotherapy, psychosocial counselling and healthcare usage in general. Furthermore, a set of self-report questionnaires on personality disorder symptoms (DSM-IV and ICD-10 Personality Questionnaire; DIP-Q), ${ }^{59}$ personality traits (Swedish Universities Scales of Personality), ${ }^{60}$ alcohol use (Alcohol Use Disorders Identification Test) ${ }^{61}$ drug use (Drug Use
Disorders Identification Test), ${ }^{62}$ somatic symptoms items (Symptom Checklist-90) ${ }^{63}$ and current depression severity (Montgomery-Åsberg Depression Rating Scale, self-report; MADRS-S) ${ }^{64}$ was administered. The assessment also included a psychometric test of social cognition (Reading the Mind in the Eyes Test), ${ }^{65}$ as well as measurements of height, weight, hip/waste ratio, body mass index, pulse and blood pressure. As regards the DIP-Q, the participants that rated above the recommended clinical cut-scores were assessed with the Structured Clinical Interview for DSM-IV axis II disorders. ${ }^{66}$ 
Table 3 Number of participants and retention rates at each stage of the data collection

\begin{tabular}{|c|c|c|c|c|c|c|}
\hline \multirow[b]{2}{*}{ Study phase } & \multirow[b]{2}{*}{$\begin{array}{l}\text { Total cohort, } \\
\mathrm{n} \\
(\%) \text { retained }\end{array}$} & \multicolumn{5}{|c|}{ Subgroups based on subtyping of adolescent depression } \\
\hline & & $\begin{array}{l}\text { Persistent } \\
\text { depressive } \\
\text { disorder, } \\
\text { n (\%) retained }\end{array}$ & $\begin{array}{l}\text { Major } \\
\text { depressive } \\
\text { disorder, } \\
\text { n (\%) retained }\end{array}$ & $\begin{array}{l}\text { Subthreshold } \\
\text { depression, } \\
\text { n (\%) retained }\end{array}$ & $\begin{array}{l}\text { Hypomanic } \\
\text { episode, } \\
\text { n (\%) retained }\end{array}$ & $\begin{array}{l}\text { No depression, } \\
\text { n (\%) retained }\end{array}$ \\
\hline $\begin{array}{l}\text { Baseline assessment, ages } \\
16-17\end{array}$ & 631 & 187 & 87 & 76 & 40 & 241 \\
\hline Biomarkers, ages 33-36 & $188(30)$ & $56(30)$ & $30(34)$ & $16(21)$ & $11(28)$ & $75(31)$ \\
\hline $\begin{array}{l}\text { Register-based follow-up, } \\
\text { approximately ages } 17-40\end{array}$ & $576(91)$ & $175(94)$ & $82(94)$ & $64(84)$ & $37(93)$ & $218(90)$ \\
\hline
\end{tabular}

\section{Reassessment and collection of biomarkers (ages 33-36)}

Participants were examined using high-frequency ultrasound on the left common carotid artery. In addition, close to 100 cardiovascular disease and inflammation markers were collected by means of blood samples, including high-sensitive C-reactive protein, total cholesterol, low/high-density lipids and triglycerides. The participants were reassessed using the modules for depressive disorders in the MINI-PLUS. They were also interviewed about known risk markers for cardiovascular disease, such as smoking and exercise. Further, a set of self-report questionnaires (MADRS-S, SCI and the Pressure-Activation-Stress scale ${ }^{67}$ ) was administered, as well as objective measurement of blood pressure, pulse, hip/ waste ratio and body mass index.

\section{Register-based follow-up (approximately ages 17-40)}

In order to facilitate a comprehensive overview of adult health and psychosocial functioning, we have currently obtained extensive data from the following Swedish government agencies: The National Board of Health and Welfare (healthcare and social services), Swedish Social Insurance Agency (sick leave), Statistics Sweden (eg, gainful employment, unemployment, education, income and migration) and the Swedish National Council for Crime Prevention (convictions). In addition, a reference group was created based on registry data for all individuals born in 1975-1976 who were registered as residents in Sweden in 1992. This reference population enables analyses of representativeness and thus makes it possible to compare cohort participants with their same-age peers from the general population with regard to longterm outcomes of interest. Further, we obtained registry data on parents of all subjects from both the reference population and the ULADS cohort. These parental data comprise sociodemographic information from the early 1990s (eg, education, occupation, disposable income, worldwide region of origin, socioeconomic classification), but also healthcare utilisation recorded in specialised outpatient (in 2001-2015) and inpatient (in 1973-2015) care settings.
National registries constitute a fundamental part of epidemiological research in Sweden, and serve users such as decision makers, government departments and various organisations. ${ }^{45}$ It should be noted that each government agency has its own measures for continuously improving completeness and overall quality. Available registry data are described in detail in online supplementary file 1 .

\section{Registries from The National Board of Health and Welfare}

The data obtained from The National Board of Health and Welfare include inpatient and outpatient care, prescribed drugs, compulsory psychiatric care, care of abusers, social assistance and mortality. The coverage for registries from The National Board of Health and Welfare is reported to be generally good. ${ }^{68-71}$ The National Patient Register (NPR) covers inpatient hospital admissions since 1969 and outpatient care since 2001 for all patients in specialised hospital care settings in Sweden. All private and public caregivers, except primary care, are required to report data to the NPR and the coverage of registration is reported to be very good. The coverage of inpatient care for all somatic and psychiatric hospital discharges is close to $100 \%$, and the overall positive predictive value for most diagnoses registered in inpatient care has been reported to be $85 \%-95 \% .^{72}$ As regards outpatient care, such as specialty mental health services and other medical outpatient care settings, the coverage of outpatient discharges is around $87 \%$. The missing $13 \%$ is mostly related to lack of reporting by private caregivers. ${ }^{69}$ The Prescribed Drug Register (PDR) includes information on all dispensed medication across all pharmacies in Sweden since July 2005, however, the PDR does not include treatment indication. ${ }^{46} 47$ The coverage is reported to be generally good, as it is regulated by Swedish law to deliver data on dispensed prescription drugs to the register holder. Data collection is mainly handled automatically by means of administration systems, however, there is a potential undercoverage of data if drugs are distributed in hospital day care instead of purchased following prescription. This applies primarily for expensive drugs. ${ }^{70}$ As regards the Register of Care of Abusers Act, missing data can 
result from delayed reporting. ${ }^{73}$ The Register of Social Assistance comprises nationwide data on various types of social welfare recipiency, including months of assistance and total expenditure each year. The coverage is reported to be generally good, although some undercoverage has been found due to non-reporting from a few municipalities during certain years. ${ }^{74}$ Lastly, the coverage of the Cause of Death Register is nearly complete, and $96 \%$ of all individuals in the register have a specific underlying cause of death recorded. ${ }^{75}$

\section{Registry from Swedish Social Insurance Agency}

The Micro-Data for Analysis of the Social Insurance System database comprises data on a large number of benefits administered by Swedish Social Insurance Agency. Of particular interest in the current project are all registered diagnoses related to absence from work or education. The coverage of such information is estimated to be good from year 2005 onwards, although the registry was originally initiated in 2002. The coverage is nearly complete for other variables included in the database. ${ }^{76}$

\section{Registries from Statistics Sweden}

The data obtained from Statistics Sweden include emigration/immigration, civil state, children, grade point average from school, higher education, employment status and income (eg, gainful employment, capital, education, sickness benefits, unemployment benefits and social assistance). Most data have been extracted from the Longitudinal Integration Database for Health Insurance and Labour Market Studies (LISA), administered by Statistics Sweden, which started in 1990 and is updated each year by the transmission of annual data from various source registries. ${ }^{77}$ The LISA database includes all individuals aged 16 or older who were registered as residents in the country. As such, LISA is based on many different administration systems and national registries. Overall, the registries have been reported to have good quality. ${ }^{78}$

\section{Registry from the Swedish National Council for Crime Prevention}

From this source we obtained data on convictions for criminal offences. The Register of Court Convictions is based on data from judicial agencies in Sweden, as conviction decisions from law courts are reported through various administration systems. All data are regularly sent to the Swedish National Council for Crime Prevention electronically, after which inspections, completions and corrections are carried out in order to ensure validity of data. The coverage of the registry is estimated to be good, although certain undercoverage is possible due to delayed reporting. ${ }^{79-81}$

\section{Cohort characteristics}

Baseline characteristics have been reported in several previous publications. ${ }^{22} 2582-85$ The most salient feature of the baseline characteristics is arguably the detailed clinical subtyping of adolescent depression available from the DICA-R-A assessments. The diagnostic assessment of adolescent mood disorders was originally based on the
Diagnostic and Statistical Manual of Mental Disorders, Third Edition-Revised (DSM-III-R) ${ }^{86}$ criteria. In order to conform to the prevailing terminology, we have subsequently applied corresponding Diagnostic and Statistical Manual of Mental Disorders, Fifth Edition (DSM-5) ${ }^{87}$ depressive disorders to the original DICA-R-A assessments. Consequently, the terms we presently use for adolescent depressive disorders are MDD and persistent depressive disorder. As screening by nature is more or less inexact, some of the screening-positive participants did not meet the criteria for a lifetime depressive disorder according to the diagnostic assessment. In contrast, some of the screening-negative participants actually met the criteria for a current or previous depressive disorder (figure 1). The former group was categorised as having subthreshold depression, while the latter was classified based on the specific disorder confirmed by the DICA-R-A assessment. It should be noted that previous depressive episodes might theoretically have occurred before adolescence. Further, a subgroup of participants met the criteria for a lifetime hypomanic episode when they were interviewed in adolescence. Since this is an exclusion criterion for depressive disorders, these participants form a separate category. Notably, a few participants in this category did not meet criteria for bipolar disorder (ie, no history of a major depressive episode). The subcategorisation is explained in further detail below.

1. MDD: The current diagnostic criteria for MDD have not changed from previous DSM-III-R definitions, with the exception that the former 'bereavement exclusion criterion' has been omitted in DSM-5. All participants with a current or lifetime major depressive episode lasting shorter than 1 year were categorised as fulfilling criteria for MDD, provided that diagnostic criteria for a past or current hypomanic episode were not met $(\mathrm{n}=87)$.

2. Persistent depressive disorder: This is defined by current DSM-5 criteria as a depressed mood occurring for most of the day, for more days than not, for at least 1 year (for children and adolescents). The disorder subsumes previous DSM-III-R and DSM-IV definitions of chronic MDD and dysthymic disorder ( $\mathrm{n}=187 ; 142$ with a concurrent major depressive episode, and 45 with dysthymia only).

3. Hypomanic episode: This is defined by DSM-5 criteria featuring a past or current full-syndromal hypomania fulfilled for a duration of at least 4 days $(n=40$; of which 36 had a history of a major depressive episode, 2 had a history of dysthymia only and 2 reported no past or current depressive disorder).

4. Subthreshold depression: By definition, this condition does not meet diagnostic criteria for a depressive disorder, as too few symptoms are manifested. In the present study, subthreshold depression was defined as positive screening but no past or current depressive disorder or hypomanic episode $(\mathrm{n}=76)$. 
5. No depression: This was defined by negative screening, no past or current depressive disorder and no past or current hypomanic episode $(\mathrm{n}=241)$.

Table 2 shows that key adolescent characteristics differed markedly between the subgroups defined above, which have also been reported in several previous publications. ${ }^{228285}$ In particular, the adolescents with persistent depressive disorder or hypomanic episodes had more severe depressive symptoms, more comorbidity and more psychosocial problems.

\section{Attrition}

The attrition rates for the subcategories outlined above, at each stage of the study, are presented in table 3. While dropout rates did not differ substantially between the depressed and non-depressed adolescents in general, participants with an adolescent subthreshold depression were more likely to drop out than other groups. Table 2 provides information about the presence of baseline characteristics in the diagnostic subgroups, both in the original sample and in the sample retained in the ongoing register-based follow-up. The minor discrepancies suggest that the representativeness of the retained sample is acceptable. As regards the recently obtained registry data, there were two major sources of missing data for the whole or part of the follow-up period: death $(n=3)$ and emigration $(\mathrm{n}=69)$. The mean total time residing abroad during the follow-up among those who had emigrated was 6.9 years $(\mathrm{SD}=5.5)$. In 2014 (currently, the last available year), 38 $(55 \%)$ of those emigrating at any time since the baseline assessment had returned and, thus, were registered as residents of Sweden.

\section{Patient and public involvement}

Patients or public were not involved in the planning or conduct of the study. Participants have been informed that they can take part of their own personal data, and have been offered the opportunity to learn more about the study as a whole. There has been considerable change in research practice during the last couple of decades. If a similar study were to be initiated today, it would be advisable to pay close attention to the viewpoints and experiences of young people with a history of depression in the planning phase.

\section{FINDINGS TO DATE}

Extensive information on the baseline assessment has previously been reported, including prevalence of depression, comorbidity, somatic symptoms, social network, family climate and life events. The 1-year and lifetime prevalence of major depression in adolescence was estimated to be $5.8 \%$ and $11.4 \%$, respectively, with four girls for each boy. Depressive disorder lasting for at least 1 year (ie, persistent depressive disorder) was the most common subtype. ${ }^{25}$ Psychiatric comorbidity was common, with anxiety disorders present in approximately half of the depressed adolescents, and conduct disorder in one-fourth. ${ }^{82}$ Adolescents with persistent depressive disorder described a particularly problematic situation, with unsatisfactory social network, conflicts within the family and multiple somatic symptoms. ${ }^{85} 88$

The follow-up interviews and analyses of registry data obtained in early adulthood (ages 30-33) have been described in several publications, focusing on a range of topics related to mental health, general health and role functioning. An increased risk of continued depressive episodes and other mental disorders in early adulthood has repeatedly been shown in other prospective cohort studies, but data from ULADS in addition showed that persistent depressive disorder is associated with a worse prognosis than MDD. This association was only partly explained by contextual factors, indicating that adolescents suffering from an extended episode of depression are predisposed to future mental health problems. ${ }^{22}$ Similarly, multiple somatic symptoms in adolescence independently predicted continued depressive episodes and other mental health concerns in early adulthood ${ }^{89}{ }^{90}$ Register-based data showed that females with adolescent depression had an increased consumption of both inpatient and outpatient care, but also more prescribed psychotropic as well as non-psychotropic drugs in early adulthood. Males with adolescent depression were more likely than controls to receive inpatient care for mental disorders, especially alcohol and drug abuse. $^{91} 92$

The publications from the follow-up in early adulthood also focused on three aspects of social functioning that are central to this phase of life: educational attainment, intimate relationships and childbearing. The depressed adolescents on average had lower grades in compulsory school and upper-secondary school and were less likely to have completed higher education by age 30 . Adjustment for grade point average and parental socioeconomic status mitigated the latter association in females, but not in males. ${ }^{41}$ Further, females with adolescent depression were more likely to report abortion, miscarriage and intimate partner violence in early adulthood. They had also divorced and become single mothers to a larger extent. These associations seemed to be moderated by comorbid disruptive behavioural disorders in adolescence. ${ }^{42}$ As for the long-term consequences of family-related adversities in adolescence, depressed adolescents with separated parents had an excess risk of recurrence of depression in adulthood. ${ }^{93}$

The long-term mental health outcome of the subgroup reporting hypomanic symptoms in adolescence has been analysed separately. Only a small proportion of this group reported episodes of hypomania or mania in early adulthood, and the overall mental health outcome of this group was similar to that of adolescents with depressive disorders in general. ${ }^{94}{ }^{95}$ While hypomania symptoms in adolescence did not seem to predict bipolar disorder in early adulthood, disruptive behavioural disorder in adolescence stood out as a specific risk factor for subsequent onset of bipolar disorder in depressed adolescents. ${ }^{96}$ 
Finally, a small pilot study has been published, preliminary suggesting early signs of change in thickness of the carotid artery intima and media in subjects with onset of depression in adolescence and subsequent recurrent episodes in adulthood. ${ }^{97}$

\section{STRENGTHS AND LIMITATIONS}

The most unique feature of the present study is the wide scope of consecutive data available from national registries for the entire follow-up period. These panoramic data sources will enable thorough analyses of overall long-term social, economic and health-related outcomes of adolescent depressive disorders. Further, the extensive data available from the face-to-face assessments at baseline and the 15-year follow-up will allow identification of potential moderation and mediation of longterm outcomes, including the impact of recurring or continued psychiatric morbidity in young adulthood. The combination of diagnostic assessments and registry data will also permit unparalleled cost-of-illness analyses regarding early-onset depression.

While longitudinal cohort studies of early-onset depression have contributed vastly to our current understanding of the natural course and long-term outcomes of the disorder, it should be noted that each of the available cohorts includes a relatively small number of cases (table 1). Due to oversampling of cases, the total number of depressed adolescents in ULADS is somewhat larger than in most comparable studies. This allows for subanalyses of diagnostic subcategories, providing a unique opportunity to gain knowledge about differential pathways in adulthood depending on depressive symptomatology in adolescence. On the other hand, this oversampling came at the cost of a less robust comparison group of non-depressed adolescents. For this reason, we have included register-based reference populations comprising the entire corresponding age group residing in Uppsala, and in Sweden at large, in 1992.

The retention rate at follow-up was high for the current register-based part of the study, but lower for the faceto-face assessment at ages 30-33 (table 3). Overall, we deem that the retention rate is acceptable given the long follow-up period. While there is a possibility that more frequent follow-up assessments would have reduced the attrition rate, such a procedure might potentially also entail increased risk of bias due to repeated measurement and instrumentation. For instance, it cannot be ruled out that frequent assessments of depressive episodes and other mental health conditions during adolescence and young adulthood do have an impact on the individual's awareness of these conditions and readiness to seek treatment. Conversely, multiple interviews may potentially facilitate disclosure of mental health problems, as frequent contact with research staff may entail a heightened sense of trust. ${ }^{98}$ While the use of register-based data bypasses potentially significant sources of bias related to instrumentation and recall bias, the validity depends on the specific type of information used and for what purpose. When it comes to objective data such as income, grade point average, days of unemployment and healthcare utilisation, valid registries have a clear advantage over self-report. For several reasons, it is more questionable to use registry data as a proxy measure of depressive episodes and other common mental disorders. First, the subjective nature of these conditions makes standardised assessments indispensable. Second, depression is often undertreated and is thereby incorrectly reflected by healthcare utilisation. ${ }^{99}$ Third, primary care data were not available due to reasons related to administration systems. Importantly, a recent study indicated that a large majority of adult individuals presenting with MDD and other common psychiatric disorders are treated in primary care only. Typically, primary care physicians have limited time to do psychiatric assessments, and the methods of diagnostic ascertainment may therefore be unreliable. ${ }^{100}$ Accordingly, we do not primarily intend to use register-based healthcare data as valid measures of occurrence of mental disorders, but rather as outcome measures signifying healthcare utilisation.

The source population of the present study was well defined, comprising a total population of firstyear students in upper secondary-schools in a specific region. However, the historical and demographic context must be taken into consideration when findings are generalised to current cohorts of adolescents. First, the availability of psychological and pharmacological treatments for adolescent depression currently recommended in clinical guidelines has improved dramatically since the early 1990s. Second, Uppsala is a university region, and the population lives in close proximity to a university hospital. The participants in the present study can be expected to have more highly educated parents than the general population, and accordingly attain a higher educational level themselves. ${ }^{41}$ Third, major societal changes have occurred in the past two decades as regards education, healthcare, social services, labour market and migration. Fourth, and finally, psychiatric epidemiology and research methodology in general have evolved since the early 1990s. Importantly, however, methods used for screening and diagnostic assessment are essentially the same.

Drawing from our own experiences, we would advise researchers currently planning similar projects to carefully consider their choice of screening procedure. Screening for depression is challenging due to the episodic nature of the disorder and does not necessarily give a complete coverage of the diverse and heterotypic nature of child and adolescent mental health conditions. ${ }^{101} 102$ This was clearly illustrated by the fact that a relatively large proportion of screening-negative peers completing the adolescent diagnostic interview in fact fulfilled the criteria of a previous major depressive episode or other mental disorders. ${ }^{22}$ For most purposes, a more general and repeated screening for behavioural and emotional problems might be more appropriate. 


\section{COLLABORATIONS}

Our research group currently includes extensive expertise in child and adolescent psychiatry, adult psychiatry, clinical psychology, public health and health economics. We believe that this interdisciplinary approach creates a sustainable arrangement for making good use of this unique data set. It is important to emphasise, though, that the generalisability of findings from a single cohort, restricted to a particular geographical region and a specific period in time, inevitably is limited. We are therefore convinced that collaboration is key to get the most out of existing cohort studies. A recent joint publication by researchers working with longitudinal studies of adolescent depression has illustrated that collaborative endeavours can be successfully realised. ${ }^{102}$ To date, ULADS has not been involved in such joint efforts, but we would certainly welcome extended collaboration with research groups working with similar datasets.

\section{Author affiliations \\ ${ }^{1}$ Department of Neuroscience, Child and Adolescent Psychiatry, Uppsala University, Uppsala, Sweden \\ ${ }^{2}$ University Health Care Research Centre, Faculty of Medicine and Health, Örebro University, Örebro, Sweden \\ ${ }^{3}$ Department of Public Health and Caring Sciences, Child Health and Parenting (CHAP), Uppsala University, Uppsala, Sweden \\ ${ }^{4}$ Department of Neuroscience, Psychiatry, Uppsala University, Uppsala, Sweden ${ }^{5}$ Center of Neurodevelopmental Disorders at Karolinska Institutet (KIND), Pediatric Neuropsychiatry Unit, Department of Women's and Children's Health, Karolinska Institutet, Stockholm, Sweden \\ ${ }^{6}$ Centre for Psychiatry Research, Stockholm Health Care Services, Stockholm County Council, Stockholm, Sweden}

Contributors G0 and ALvK initiated this study in the early 1990s. UJ, HB, APä, IA, LvK, GO and ALvK conducted the 15-year follow-up. HB had primary responsibility for the collection of biomarkers. IA, APh, RS, LH, IF, FS, MM, MR, HB, LvK, ALvK and UJ have planned and prepared the current phase of the study. HA has provided statistical expertise at each stage of the study. IA, APh, LH, HB and UJ drafted the manuscript. All authors are responsible for and involved in the project and have critically revised the manuscript. All authors have read and approved the final manuscript.

Funding The study is currently supported by the Swedish Research Council (grant number 2014-10092), the Uppsala-Örebro Regional Research Council (grant numbers RFR-738411; RFR-652841), the Uppsala County Council's Funds for Clinical Research (LUL-713161) and the Medical Training and Research Agreement Funds (ALF) from Uppsala University Hospital. Support has also been provided at different stages of the study by the Swedish Council for Working Life and Social Research, the Märta and Nicke Nasvell Foundation, the Clas Groschinsky Memorial Fund, the Söderström-Königska Foundation, and the Foundation in Memory of Professor Bror Gadelius.

Disclaimer The funders had no role in study design, data collection, analysis, decision to publish, or preparation of this manuscript or previous publications.

Competing interests None declared.

Patient consent for publication Not required.

Ethics approval The original study was approved by the Ethical Committee of Uppsala University. For each new phase of the study, ethical approvals have been obtained. Since 2003, Sweden has a new Ethical Review Act (2003:460). Each subsequent phase has accordingly been approved by the Regional Ethical Review Board in Uppsala, including the current phase (2015/449/1-2).

Provenance and peer review Not commissioned; externally peer reviewed.

Data sharing statement Regulations regarding data from the Swedish national registries prevent us from sharing data openly.
Open access This is an open access article distributed in accordance with the Creative Commons Attribution Non Commercial (CC BY-NC 4.0) license, which permits others to distribute, remix, adapt, build upon this work non-commercially, and license their derivative works on different terms, provided the original work is properly cited, appropriate credit is given, any changes made indicated, and the use is non-commercial. See: http://creativecommons.org/licenses/by-nc/4.0/.

\section{REFERENCES}

1. Gore FM, Bloem PJN, Patton GC, et al. Global burden of disease in young people aged 10-24 years: a systematic analysis. The Lancet 2011;377:2093-102.

2. Vos T, Barber RM, Bell B, et al. Global, regional, and national incidence, prevalence, and years lived with disability for 301 acute and chronic diseases and injuries in 188 countries, 1990-2013: a systematic analysis for the Global Burden of Disease Study 2013. The Lancet 2015;386:743-800.

3. Otte C, Gold SM, Penninx BW, et al. Major depressive disorder. Nat Rev Dis Primers 2016;2:16065.

4. Kessler RC, Bromet EJ. The epidemiology of depression across cultures. Annu Rev Public Health 2013;34:119-38.

5. Chisholm D, Sweeny K, Sheehan P, et al. Scaling-up treatment of depression and anxiety: a global return on investment analysis. Lancet Psychiatry 2016;3:415-24.

6. Chiu M, Lebenbaum M, Cheng J, et al. The direct healthcare costs associated with psychological distress and major depression: A population-based cohort study in Ontario, Canada. PLoS One 2017;12:e0184268.

7. Ekman M, Granström O, Omérov S, et al. The societal cost of depression: evidence from 10,000 Swedish patients in psychiatric care. J Affect Disord 2013;150:790-7.

8. Hu TW. Perspectives: an international review of the national cost estimates of mental illness, 1990-2003. J Ment Health Policy Econ 2006:9:3-13.

9. von Knorring L, Akerblad AC, Bengtsson F, et al. Cost of depression: effect of adherence and treatment response. Eur Psychiatry 2006;21:349-54.

10. Bromet E, Andrade LH, Hwang I, et al. Cross-national epidemiology of DSM-IV major depressive episode. BMC Med 2011;9:90.

11. Seedat S, Scott KM, Angermeyer MC, et al. Cross-national associations between gender and mental disorders in the World Health Organization World Mental Health Surveys. Arch Gen Psychiatry 2009;66:785-95.

12. Costello EJ, Egger H, Angold A. 10-year research update review: the epidemiology of child and adolescent psychiatric disorders: I. Methods and public health burden. J Am Acad Child Adolesc Psychiatry 2005;44:972-86.

13. Hyde JS, Mezulis AH, Abramson LY. The ABCs of depression: integrating affective, biological, and cognitive models to explain the emergence of the gender difference in depression. Psychol Rev 2008;115:291-313.

14. Jane Costello E, Erkanli A, Angold A. Is there an epidemic of child or adolescent depression? J Child Psychol Psychiatry 2006;47:1263-71.

15. Hankin BL, Abramson LY, Moffitt TE, et al. Development of depression from preadolescence to young adulthood: emerging gender differences in a 10-year longitudinal study. J Abnorm Psychol 1998;107:128-40.

16. Lewinsohn PM, Rohde P, Klein DN, et al. Natural course of adolescent major depressive disorder: I. Continuity into young adulthood. J Am Acad Child Adolesc Psychiatry 1999;38:56-63.

17. Bertha EA, Balázs J. Subthreshold depression in adolescence: a systematic review. Eur Child Adolesc Psychiatry 2013;22:589-603.

18. Wesselhoeft R, Sørensen MJ, Heiervang ER, et al. Subthreshold depression in children and adolescents - a systematic review. J Affect Disord 2013;151:7-22.

19. Copeland WE, Wolke D, Shanahan L, et al. Adult Functional Outcomes of Common Childhood Psychiatric Problems: A Prospective, Longitudinal Study. JAMA Psychiatry 2015;72:892-9.

20. Thapar A, Collishaw S, Pine DS, et al. Depression in adolescence. The Lancet 2012;379:1056-67.

21. Colman I, Wadsworth ME, Croudace TJ, et al. Forty-year psychiatric outcomes following assessment for internalizing disorder in adolescence. Am J Psychiatry 2007;164:126-33.

22. Jonsson $\mathrm{U}$, Bohman $\mathrm{H}$, von Knorring $\mathrm{L}$, et al. Mental health outcome of long-term and episodic adolescent depression: 15 -year follow-up of a community sample. J Affect Disord 2011;130:395-404. 
23. Johnson D, Dupuis G, Piche J, et al. Adult mental health outcomes of adolescent depression: a systematic review. Depress Anxiety 2018;35:700-16.

24. Lewinsohn PM, Hops H, Roberts RE, et al. Adolescent psychopathology: I. Prevalence and incidence of depression and other DSM-III-R disorders in high school students. J Abnorm Psychol 1993;102:133-44.

25. Olsson GI, von Knorring AL. Adolescent depression: prevalence in Swedish high-school students. Acta Psychiatr Scand 1999;99:324-31.

26. Naicker K, Galambos NL, Zeng Y, et al. Social, demographic, and health outcomes in the 10 years following adolescent depression. Adolesc Health 2013;52:533-8.

27. Anderson JC, Williams S, McGee R, et al. DSM-III disorders in preadolescent children. Prevalence in a large sample from the general population. Arch Gen Psychiatry 1987;44:69-76.

28. Costello EJ, Mustillo S, Erkanli A, et al. Prevalence and development of psychiatric disorders in childhood and adolescence. Arch Gen Psychiatry 2003;60:837-44.

29. Fergusson DM, Horwood LJ, Ridder EM, et al. Subthreshold depression in adolescence and mental health outcomes in adulthood. Arch Gen Psychiatry 2005;62:66-72.

30. Lewinsohn PM, Shankman SA, Gau JM, et al. The prevalence and co-morbidity of subthreshold psychiatric conditions. Psychol Med 2004;34:613-22.

31. Farmer RF, Kosty DB, Seeley JR, et al. Aggregation of lifetime Axis I psychiatric disorders through age 30: incidence, predictors, and associated psychosocial outcomes. J Abnorm Psychol 2013;122:573-86

32. Brière FN, Rohde P, Seeley JR, et al. Adolescent suicide attempts and adult adjustment. Depress Anxiety 2015;32:270-6.

33. Frost LA, Moffitt TE, McGee R. Neuropsychological correlates of psychopathology in an unselected cohort of young adolescents. $J$ Abnorm Psychol 1989;98:307-13.

34. McGee R, Feehan M, Williams S, et al. DSM-III disorders in a large sample of adolescents. J Am Acad Child Adolesc Psychiatry 1990;29:611-9.

35. Feehan M, McGee R, Raja SN, et al. DSM-III-R disorders in New Zealand 18-year-olds. Aust N Z J Psychiatry 1994;28:87-99.

36. Poulton R, Moffitt TE, Silva PA. The Dunedin Multidisciplinary Health and Development Study: overview of the first 40 years, with an eye to the future. Soc Psychiatry Psychiatr Epidemiol 2015;50:679-93.

37. McLeod GF, Horwood LJ, Fergusson DM, et al. Adolescent depression, adult mental health and psychosocial outcomes at 30 and 35 years. Psychol Med 2016;46:1401-12.

38. McLeod GF, Fergusson DM, John Horwood L, et al. Adiposity and psychosocial outcomes at ages 30 and 35. Soc Psychiatry Psychiatr Epidemiol 2016;51:309-18.

39. Shanahan L, Copeland WE, Costello EJ, et al. Child-, adolescentand young adult-onset depressions: differential risk factors in development? Psychol Med 2011;41:2265-74.

40. Costello EJ, Copeland W, Angold A. The Great Smoky Mountains Study: developmental epidemiology in the southeastern United States. Soc Psychiatry Psychiatr Epidemiol 2016;51:639-46.

41. Jonsson U, Bohman $\mathrm{H}$, Hjern A, et al. Subsequent higher education after adolescent depression: a 15-year follow-up register study. Eur Psychiatry 2010;25:396-401.

42. Jonsson $\mathrm{U}$, Bohman $\mathrm{H}$, Hjern $\mathrm{A}$, et al. Intimate relationships and childbearing after adolescent depression: a population-based 15 year follow-up study. Soc Psychiatry Psychiatr Epidemiol 2011;46:711-21.

43. Clayborne ZM, Varin M, Colman I. Systematic Review and MetaAnalysis: Adolescent Depression and Long-Term Psychosocial Outcomes. J Am Acad Child Adolesc Psychiatry 2019;58:72-9.

44. Lewinsohn PM, Rohde P, Seeley JR, et al. Psychosocial functioning of young adults who have experienced and recovered from major depressive disorder during adolescence. J Abnorm Psychol 2003;112:353-63.

45. Ludvigsson JF, Almqvist C, Bonamy AK, et al. Registers of the Swedish total population and their use in medical research. Eur $J$ Epidemiol 2016;31:125-36.

46. Wallerstedt SM, Wettermark B, Hoffmann M. The First Decade with the Swedish prescribed drug register - a systematic review of the output in the scientific literature. Basic Clin Pharmacol Toxicol 2016;119:464-9.

47. Wettermark B, Hammar N, Fored CM, et al. The new Swedish prescribed drug register--opportunities for pharmacoepidemiological research and experience from the first six months. Pharmacoepidemiol Drug Saf 2007;16:726-35.

48. Beck AT, Ward CH, Mendelson M, et al. An inventory for measuring depression. Arch Gen Psychiatry 1961;4:561-71.
49. Schoenbach VJ, Kaplan BH, Grimson RC, et al. Use of a symptom scale to study the prevalence of a depressive syndrome in young adolescents. Am J Epidemiol 1982;116:791-800.

50. Larsson B, Melin L. Depressive symptoms in Swedish adolescents. J Abnorm Child Psychol 1990;18:91-103.

51. Roberts RE, Lewinsohn PM, Seeley JR. Screening for adolescent depression: a comparison of depression scales. J Am Acad Child Adolesc Psychiatry 1991;30:58-66.

52. Reich W, Herjanic B, Welner Z, et al. Development of a structured psychiatric Interview for children: Agreement on diagnosis comparing child and parent interviews. J Abnorm Child Psychol 1982;10:325-36.

53. Schalling D, Asberg M, Edman G, et al. Markers for vulnerability to psychopathology: temperament traits associated with platelet MAO activity. Acta Psychiatr Scand 1987;76:172-82.

54. Coddington RD. The significance of life events as etiologic factors in the diseases of children. II. A study of a normal population. $J$ Psychosom Res 1972;16:205-13.

55. Henderson S, Byrne DG, Duncan-Jones P, et al. Social bonds in the epidemiology of neurosis: a preliminary communication. $\mathrm{Br} J$ Psychiatry 1978;132:463-6.

56. Undén AL, Orth-Gomér K. Development of a social support instrument for use in population surveys. Soc Sci Med 1989;29:1387-92.

57. Larsson BS. Somatic complaints and their relationship to depressive symptoms in Swedish adolescents. J Child Psychol Psychiatry 1991;32:821-32.

58. Sheehan DV, Lecrubier $Y$, Sheehan $\mathrm{KH}$, et al. The Mini-International Neuropsychiatric Interview (M.I.N.I.): the development and validation of a structured diagnostic psychiatric interview for DSMIV and ICD-10. J Clin Psychiatry 1998;59:22-33. quiz 34-57.

59. Ottosson H, Bodlund O, Ekselius L, et al. DSM-IV and ICD10 personality disorders: a comparison of a self-report questionnaire (DIP-Q) with a structured interview. Eur Psychiatry 1998;13:246-53.

60. Gustavsson JP, Bergman $\mathrm{H}$, Edman $\mathrm{G}$, et al. Swedish universities Scales of Personality (SSP): construction, internal consistency and normative data. Acta Psychiatr Scand 2000;102:217-25.

61. Reinert DF, Allen JP. The alcohol use disorders identification test: an update of research findings. Alcohol Clin Exp Res 2007;31:185-99.

62. Berman $\mathrm{AH}$, Bergman $\mathrm{H}$, Palmstierna $\mathrm{T}$, et al. Evaluation of the Drug Use Disorders Identification Test (DUDIT) in criminal justice and detoxification settings and in a Swedish population sample. Eur Addict Res 2005;11:22-31.

63. Derogatis LR, Savitz KL. The SCL-90-R, Brief Symptom Inventory and Matching Clinical Rating Scales. In: Maruish ME, ed. The use of psychological testing for treatment planning and outcomes assessment. Philadelphia: Lawrence Erlbaum, 1999:679-724.

64. Svanborg P, Asberg M. A comparison between the Beck Depression Inventory $(\mathrm{BDI})$ and the self-rating version of the Montgomery Asberg Depression Rating Scale (MADRS). J Affect Disord 2001;64(2-3):203-16

65. Baron-Cohen S, Wheelwright S, Hill J, et al. The "Reading the Mind in the Eyes" Test revised version: a study with normal adults, and adults with Asperger syndrome or high-functioning autism. J Child Psychol Psychiatry 2001;42:241-51.

66. First MB, Gibbon M, Spitzer RL et al. Structured Clinical Interview for DSM-IV Axis II Personality Disorders, (SCID-II). Washington, D.C American Psychiatric Press, Inc, 1997.

67. Lindblad F, Backman L, Akerstedt T. Immigrant girls perceive less stress. Acta Paediatr 2008;97:889-93.

68. Socialstyrelsen. (The National Board of Health and Welfare). Ekonomiskt bistånd årsstatistik 2014. Belopp samt antal biståndsmottagare och antal biståndshushåll.. http://www. socialstyrelsen.se/Lists/Artikelkatalog/Attachments/19842/2015-68.pdf (Accessed Jun 2018).

69. Socialstyrelsen. The National Board of Health and Welfare). Kodningskvalitet i patientregistret: Ett nytt verktyg för att mäta kvalitet. https://www.socialstyrelsen.se/Lists/Artikelkatalog/ Attachments/19005/2013-3-10.pdf (Accessed Jun 2018).

70. Socialstyrelsen. The National Board of Health and Welfare). Kvalitetsdeklaration: Statistik om läkemedel år. 2016 https:// www.socialstyrelsen.se/SiteCollectionDocuments/2017-3-33Kvalitetsdeklaration.pdf (Accessed Jun 2018).

71. Socialstyrelsen. The National Board of Health and Welfare). Kvalitetsdeklaration: Statistik om dödsorsaker. 2016 https://www. scb.se/contentassets/692abc00759c49b99539fc4bc92a2feb/ hs0301_kd 2016.pdf (Accessed Jun 2018).

72. Ludvigsson JF, Andersson E, Ekbom A, et al. External review and validation of the Swedish national inpatient register. BMC Public Health 2011;11:450. 
73. Socialstyrelsen. The National Board of Health and Welfare). Registret över tvångsvård enligt lagen om vård av missbrukare i vissa fall. http://www.socialstyrelsen.se/register/socialtjanstregister/ tvangsvardlvm (Accessed Jun 2018).

74. Socialstyrelsen. The National Board of Health and Welfare). Kvalitetsdeklaration: Ekonomiskt bistånd. https://www. socialstyrelsen.se/SiteCollectionDocuments/2017-9-16kvalitetsdeklaration.pdf (Accessed Jun 2018).

75. Brooke HL, Talbäck M, Hörnblad J, et al. The Swedish cause of death register. Eur J Epidemiol 2017;32:765-73.

76. I Försäkringskassans datalager STORE. (Swedish Social Insurance Agency). MiDAS, sjukpenning och rehabiliteringspenning. https:// www.forsakringskassan.se/wps/wcm/connect/f1e0dce5-e3104d6d-8076-d4493534c10b/MiDAS_Sjukpenning_och_rehabiliteri ngspenning Version 1 02.pdf?MOD=AJPERES (Accessed Jun 2018).

77. Centralbyrån S. (Statistics Sweden). Longitudinell integrationsdatabas för sjukförsäkrings- och arbetsmarknadsstudier (LISA). http://www.scb.se/lisa/ (Accessed Jun 2018).

78. centralbyrån S. (Statistics Sweden). Preliminär befolkningsstatistik. 2016 http://www.scb.se/Statistik/BE/BE0101/_dokument/BE0101_ BS_2016_TJ_160310_Prel.pdf (Accessed Jun 2018).

79. Rådet B. (The Swedish National Council for Crime Prevention). Personer lagförda för brott. 2015 http://www.bra.se/download/18 25f91bdc15453b49d0f9605b/1464680234580/Sammanfattning_ lagforda_2015.pdf (Accessed Jun 2018).

80. Rådet B. (The Swedish National Council for Crime Prevention). Kvalitetsdeklaration: Personer lagförda för brott. https://www.scb. se/contentassets/49c3709dd82b42faacbd1ae429d9c33c/rv0201_ kd_2017_kh_180531.pdf (Accessed Jun 2018).

81. rådet B. (The Swedish National Council for Crime Prevention). Kvalitetsdeklaration: Återfall i brott - preliminär statistik. https://www.bra.se/download/18.62fc8fb415c2ea106932e7f/ 1496214697624/KVALITETSDEKLARATION_Aterfall+i+brott Preliminar_statistik_2014.pdf (Accessed Jun 2018).

82. Olsson G. Adolescent depression. epidemiology, nosology, life stress and social network. Minireview based on a doctoral thesis. Ups J Med Sci 1998;103:77-145.

83. Olsson G, von Knorring AL. Depression among Swedish adolescents measured by the self-rating scale Center for Epidemiology Studies-Depression Child (CES-DC). Eur Child Adolesc Psychiatry 1997;6:81-7.

84. Olsson G, von Knorring AL. Beck's Depression Inventory as a screening instrument for adolescent depression in Sweden: gender differences. Acta Psychiatr Scand 1997;95:277-82.

85. Olsson Gl, Nordström ML, Arinell H, et al. Adolescent depression: social network and family climate--a case-control study. J Child Psychol Psychiatry 1999;40:227-37.

86. American Psychiatric Association. Diagnostic and statistical manual of mental disorders. 3rd edn. Washington, DC: American Psychiatric Association, 1987.

87. American Psychiatric Association. Diagnostic and statistical manual of mental disorders. 5th edn. Arlington, VA: American Psychiatric Association, 2013.
88. Bohman H, Jonsson U, Von Knorring AL, et al. Somatic symptoms as a marker for severity in adolescent depression. Acta Paediatr 2010;99:1724-30.

89. Bohman $\mathrm{H}$, Jonsson $\mathrm{U}$, Päären $\mathrm{A}$, et al. Prognostic significance of functional somatic symptoms in adolescence: a 15-year community-based follow-up study of adolescents with depression compared with healthy peers. BMC Psychiatry 2012;12:90.

90. Bohman H, Låftman SB, Cleland N, et al. Somatic symptoms in adolescence as a predictor of severe mental illness in adulthood: a long-term community-based follow-up study. Child Adolesc Psychiatry Ment Health 2018;12:42.

91. Bohman $\mathrm{H}$, Jonsson U, Päären $\mathrm{A}$, et al. Long-term follow-up of adolescent depression. A population-based study. Ups J Med Sci 2010;115:21-9.

92. Päären A, von Knorring L, Jonsson U, et al. Drug prescriptions of adults with adolescent depression in a community sample. Pharmacoepidemiol Drug Saf 2012;21:130-6.

93. Bohman H, Låftman SB, Päären $\mathrm{A}$, et al. Parental separation in childhood as a risk factor for depression in adulthood: a community-based study of adolescents screened for depression and followed up after 15 years. BMC Psychiatry 2017;17:117.

94. Päären $\mathrm{A}$, Bohman $\mathrm{H}$, von Knorring $\mathrm{AL}$, et al. Hypomania spectrum disorder in adolescence: a 15-year follow-up of non-mood morbidity in adulthood. BMC Psychiatry 2014;14:9.

95. Päären $A$, von Knorring $A L$, Olsson $G$, et al. Hypomania spectrum disorders from adolescence to adulthood: a 15-year follow-up of a community sample. J Affect Disord 2013;145:190-9.

96. Päären $\mathrm{A}$, Bohman $\mathrm{H}$, von Knorring $\mathrm{L}$, et al. Early risk factors for adult bipolar disorder in adolescents with mood disorders: a 15-year follow-up of a community sample. BMC Psychiatry 2014;14:363.

97. Bohman $\mathrm{H}$, Jonsson $\mathrm{U}$, Von Knorring $\mathrm{AL}$, et al. Thicker carotid intima layer, thinner media layer and higher intima/media ratio in women with recurrent depressive disorders: a pilot study using non-invasive high frequency ultrasound. World $J$ Biol Psychiatry 2010:11:71-5.

98. Schaefer JD, Caspi A, Belsky DW, et al. Enduring mental health: prevalence and prediction. $J$ Abnorm Psychol 2017;126:212-24.

99. Thornicroft G, Chatterji S, Evans-Lacko S, et al. Undertreatment of people with major depressive disorder in 21 countries. $\mathrm{Br} \mathrm{J}$ Psychiatry 2017;210:119-24.

100. Sundquist $\mathrm{J}$, Ohlsson $\mathrm{H}$, Sundquist $\mathrm{K}$, et al. Common adult psychiatric disorders in Swedish primary care where most mental health patients are treated. BMC Psychiatry 2017;17:235.

101. Copeland WE, Shanahan L, Costello EJ, et al. Childhood and adolescent psychiatric disorders as predictors of young adult disorders. Arch Gen Psychiatry 2009;66:764-72.

102. Copeland WE, Adair CE, Smetanin P, et al. Diagnostic transitions from childhood to adolescence to early adulthood. J Child Psychol Psychiatry 2013;54:791-9. 